\title{
Delitos contra el honor militar. Homosexualidad y violencia sexual en causas militares durante la última dictadura (1976-1983) ${ }^{1}$
}

\section{Crimes against military honor. Homosexuality and sexual violence in military causes during the last dictatorship (1976-1983)}

\author{
Jazmín Lavintman \\ Facultad de Filosofía y Letras, Universidad de Buenos Aires (Argentina) \\ laviajazmin@gmail.com \\ Victoria Álvarez \\ Universidad Nacional de General Sarmiento, \\ Consejo Nacional de Investigaciones Científicas y Técnicas, \\ Facultad de Filosofía y Letras, Universidad de Buenos Aires (Argentina) \\ victoria.alvarez.tornay@gmail.com
}

\begin{abstract}
Resumen
En el Archivo Histórico de la Justicia Militar se encuentran una serie de sumarios relativos a causas ocurridas durante la última dictadura militar (1976-1983) caratulados como "delito contra el honor militar". En estos sumarios se toman las relaciones homosexuales como un delito militar punible y, también, se pueden encontrar denuncias de soldados conscriptos por haber sido abusados sexualmente por sus superiores (caratulados de la misma manera).

En el presente trabajo centraremos la mirada particularmente en dos casos denunciados. Luego de reconstruirlos, analizaremos la construcción de sentidos sobre la (homo) sexualidad masculina y reflexionaremos sobre las concepciones que subyacen a la normativa militar, que consideraba las relaciones sexuales entre personas del mismo sexo como un delito contra el honor militar asignándole la pena de prisión y/o la baja de la institución. Al analizar estas causas podemos entrever las concepciones de las Fuerzas Armadas sobre la (homo) sexualidad, la distancia entre las normativas y las prácticas, así como también la presencia de la violencia sexual en la formación militar.

Por último, más allá de la rigidez de las normas y de la naturalidad con la que parece haberse vivido la violencia sexual en dichos ámbitos, intentaremos dar cuenta de resistencias y usos subversivos de la heteronorma.
\end{abstract}

\section{Palabras Clave}

\footnotetext{
${ }^{1}$ Una primera versión de este trabajo fue presentada en las V Jornadas Historia, géneros y política en los '70 "En los desbordes de una década intensa", Instituto Interdisciplinario de Estudios de Género, Facultad de Filosofía y Letras, Universidad de Buenos Aires, el 8 de noviembre de 2018. Agradecemos las sugerencias de las comentaristas que nos permitieron enriquecer este análisis.

Esta obra está sujeta a la Licencia Reconocimiento-NoComercial-CompartirIgual 4.0 Internacional de Creative Commons. http://creativecommons.org/licenses/by-nc-sa/4.0/ 


\title{
Jazmín Lavintman - Victoria Álvarez
}

delitos contra el honor militar; homosexualidad; violencia sexual; tribunales militares; última dictadura militar argentina.

\begin{abstract}
In the Historical Archive of the Military Justice are a series of summaries related to causes that occurred during the last military dictatorship (1976-1983), which were labeled as "crime against military honor". In these summaries homosexual relations are considered as a punishable military crime and also complaints can be found of soldiers for have been sexually abused by their superiors (caratulates in the same way).

In this work the analysis will focus on two summaries about "crimes against the honor". Firstly, we will present the cases and we will analyze the construction of the meanings about (homo) sexuality. Also we will reflect on the concepts that underlie military regulations, which consider same-sex sexual relations as a offense against military honor by assigning the prison sentence and/or discharge from the institution. Both cases in relation to the repetition of complaints and mechanisms to discourage them, it is evident how the Armed Forces considered homosexuality, as well as that sexual violence was present in military training.

Finally, beyond the rigid regulations and naturalness with which sexual violence seems to have had experienced, we will attempt to show resistance acts and subversive uses of heteronormativity.
\end{abstract}

\section{Keywords}

crimes against military honor; homosexuality; sexual violence; military courts; last argentine military dictatorship.

\section{Introducción}

Como ha señalado la pionera investigación de Judith Filc, la última dictadura militar argentina fue estructurada sobre patrones de género que valoraban el rol "tradicional" de la madre-esposa como cuidadora de las próximas generaciones y, por tanto, del proyecto de Nación. La metáfora de la nación como una "buena familia cristiana" permitió la naturalización del orden social, generando la apariencia de una sociedad formada por una serie de células-familias cerradas, unidas por el parentesco, en la cual las relaciones entre el Estado y la ciudadanía se definían como relaciones familiares naturales: la pertenencia de las personas a la "familia argentina" no dependía del parentesco sino de la conducta. Como señala la autora, aquellos/as que no se comportaran "naturalmente" no podrían formar parte de dicha "familia" (Filc, 1997).

Estas concepciones fueron centrales en el mensaje que la dictadura militar buscaba dirigir a la ciudadanía: el reforzamiento de la institución familiar en su sentido occidental y cristiano. Desde esta perspectiva, en la familia heterosexual -célula básica de la sociedad- se debía formar al "ser argentino" (pensado y enunciado en masculino) y allí la mujer debía cumplir un rol esencial siendo la garante en el ámbito privado de ese modelo (Andújar et al., 2005). Este mismo constructo discursivo conservador atravesó las prácticas represivas ejercidas por los agentes del Estado en distintos contextos: en la casa durante los allanamientos, en los centros clandestinos de detención así como también en la formación militar. En cada uno de estos espacios se ejercieron violencias que tomaron, en muchos casos, 


\section{Delitos contra el honor militar. Homosexualidad y violencia sexual en causas militares durante la última dictadura (1976-1983)}

formas generizadas y sexuadas. Así, la sexualidad y el género vehiculizaron las formas de la represión política (D’Antonio, 2014; Álvarez, 2015), aunque no pueda afirmarse que la diversidad sexual fue objeto de una política represiva sistemática específica. En este sentido, durante la última dictadura militar "no se encontraron referencias sobre la persecución a personas en razón de su identidad sexual o de género ni en los organismos de derechos humanos ni en los recientemente desclasificados archivos de la represión" (Insasuti, 2015: 68).

Como se ha analizado en distintas investigaciones, la represión estatal a las prácticas homoeróticas tenía una larga historia que se expresaba en el accionar de la medicina, del derecho, de la criminología y de las fuerzas de seguridad (Acha y Ben, 2004; Fernández, 2015; Insasuti, 2015). En el caso de las Fuerzas Armadas, la sanción del Código de Justicia Militar en 1951 incluyó la figura del delito contra el honor militar que penaba, entre otros delitos, al "personal que practicare actos deshonestos con personas del mismo sexo" (art 765, CJM), que "se convirtió en una herramienta de las Fuerzas Armadas para sancionar la 'desviación' sexual masculina" (Fernández, 2018: 2). A partir de ese momento, el sexo entre varones comenzó a ser explícitamente juzgado en tribunales militares. Así, en el Archivo Histórico de la Justicia Militar ${ }^{2}$ se encuentran una serie de sumarios caratulados como "delito contra el honor militar" en los cuales las relaciones homosexuales se toman como un delito militar punible, así como también figuran denuncias de soldados conscriptos o cabos (el rango más bajo dentro de la suboficialidad) por abuso sexual de personal superior ${ }^{3}$. Sin embargo, si bien el código tenía ya más de dos décadas, durante el período particular del terrorismo de Estado en Argentina encontramos una cantidad mayor de causas con algunas características peculiares que nos proponemos analizar.

Así, en el presente trabajo pretendemos, en primer lugar, dar cuenta de algunos aspectos de la justicia militar como el rol de los tribunales militares, sus atribuciones y definiciones sobre los "delitos contra el honor militar" con el objetivo de dar un encuadre a su funcionamiento. En segundo lugar, nos detendremos en el análisis de dos sumarios de la justicia militar que tratan sobre este tipo de delito, a fin de indagar las concepciones circulantes en las Fuerzas Armadas sobre las relaciones entre personas del mismo sexo y, al mismo tiempo, evaluar la presencia de la violencia sexual en la formación militar. Por último, intentaremos dar cuenta de resistencias y usos subversivos de la heteronormatividad, retomando algunos aportes del feminismo que nos permiten dar cuenta de la agencia que aquellos militares subalternos pudieron tener en un contexto claramente hostil al ejercicio de la homosexualidad.

Es importante mencionar que, al abordar estos documentos de archivo, no los analizaremos de forma literal en relación al contenido de los hechos allí narrados,

\footnotetext{
2 Esta documentación fue desclasificada mediante Decreto № 4/2010 del Poder Ejecutivo, el 5 de enero de 2010 y transferida al Archivo General de la Nación -Departamento de Archivo Intermedio. El fondo del Consejo Supremo de Justicia Militar es de carácter público.

${ }^{3}$ Nos referimos aquí a personal de grados mayores, con una jerarquía superior.
} 


\title{
Jazmín Lavintman - Victoria Álvarez
}

ya que no se han constatado mediante otras fuentes, sino que más bien se nos presentan como formas de adentrarnos en el funcionamiento de la justicia militar, específicamente en relación a la homosexualidad y las formas punitivas que tomaba dentro de la institución militar. Asimismo debemos mencionar que no se han utilizado los apellidos originales de las personas en el sumario, sino que los modificamos teniendo en cuenta la ley de datos personales ${ }^{4}$.

\section{Los tribunales militares y los delitos contra el honor militar}

La justicia militar se fue consolidando históricamente sobre una concepción basada en que la idea de que la institución militar se diferenciaba del resto de la sociedad y, por ello, desarrolló su propio sistema de justicia. Como ha señalado Débora D'Antonio,

\begin{abstract}
"La justicia militar se organizó hacia fines del siglo XIX y comienzos del XX en la Argentina por medio de diferentes códigos que contienen normas administrativas, disciplinarias, penales y procesales aplicables al conjunto de las Fuerzas Armadas. Esta modernización y especialización se llevó a cabo en el marco de un Estado nacional que tenía unas pocas décadas de existencia y que tuvo por finalidad tanto apuntalar un espacio de legitimación corporativo como mantener el orden y la disciplina de una institución que comenzaba a percibirse a sí misma como apartada del resto de la sociedad" (2016: 2).
\end{abstract}

Así, los delitos se arbitraban únicamente en tribunales militares con procedimientos judiciales propios ${ }^{5}$. D’Antonio (2016) analizó la forma en que los consejos de guerra militares contribuyeron también al juzgamiento de civiles en manos de los tribunales militares. Sin embargo, como señala Máximo Fernández (2018), esta expansión de la jurisdicción militar sobre el fuero civil no se dio en relación a los "delitos contra el honor militar" ya que los tribunales castrenses no extendieron el juzgamiento a civiles en casos de homosexualidad. Es por esto que los sumarios que analizaremos se dieron exclusivamente en ámbitos militares.

El delito contra el honor militar según el Código de Justicia Militar (en adelante, CJM) contemplaba diversos tipos de infracciones: como el hecho de "ultrajar públicamente a la Nación o cualquiera de sus símbolos o a las Fuerzas Armadas" (artículo 758, ley 14029), el delito de cobardía asociado a huir en un enfrentamiento o a causar intencionalmente una falsa alarma ${ }^{6}$ (artículos 648 y 649), también incluía

\footnotetext{
${ }^{4}$ Ley 25.326, de Protección de Datos Personales y Sensibles.

5 En febrero del año 2009 se sanciona la ley 26394 que redujo al máximo la jurisdicción militar y realizó una importante reforma del sistema de justicia, con un trasvasamiento del fuero militar al civil.

${ }^{6}$ Sin embargo, en el artículo 760 establece formas de remendar el delito, quien habiendo incurrido en el delito de cobardía y volviere al combate demostrando dignidad, será penado solamente con una sanción disciplinaria. Además, "quedará exento de toda sanción si diese pruebas de extraordinario valor, realizando algún acto heroico" (art 760). Pudiendo ser perdonado por la institución solamente si el acto heroico 'supera' al deshonroso.
} 


\section{Delitos contra el honor militar. Homosexualidad y violencia sexual en causas militares durante la última dictadura (1976-1983)}

señales de menosprecio como quien "devolviera despachos, nombramientos o diplomas de honor o se despojare de sus insignias" (artículo 760). Asimismo, la infracción que consiste en calumniar o injuriar a otro militar de igual rango (artículo 770).

Además debemos señalar dos pasajes que interesan especificamente al presente trabajo, los artículos $765^{7}$ y 766 . El primero comprendía el "acto homosexual" estableciendo que:

"El militar que practicare actos deshonestos con persona del mismo sexo dentro o fuera de lugar militar, será degradado y condenado a prisión, si fuere oficial; reprimido con prisión menor y destituído, si fuere suboficial o clase; y si fuere soldado será condenado a prisión menor. (Artículo 765, CJM)

De esta manera el artículo 765 se proponía especificar los actos sexuales entre personas del mismo sexo como una figura particular entre los actos deshonestos que no solamente se penalizaba si se realizaba en la esfera militar, sino también incluía la esfera privada. Asimismo, el párrafo siguiente contemplaba, bajo el mismo delito, las situaciones en las que el ocurría con violencia o abuso de autoridad, con la diferencia de que cambiaba el peso de la pena:

El que ejerciere violencia, amenaza, abuso de autoridad o cualquier otro medio de intimidación o coerción, para realizar el acto a que se refiere el párrafo anterior, será reprimido con degradación y reclusión de ocho a quince años, si es oficial; con reclusión de cinco a diez años y destitución, si fuere suboficial o clase; $y$, con prisión mayor si fuere soldado" (Artículo 765, CJM).

En el artículo 766 incluía "cualquier otro de los actos deshonestos que afrentan a un hombre y rebajan su dignidad, será destituido si fuere oficial, y condenado a tres años de confinamiento, si fuere suboficial, clase o tropa" (Artículo 766, CJM). Para ahondar en el propio análisis de la institución sobre estos dos últimos artículos, en el apartado de "infracciones militares en particular" se especifica:

"La infracción configurada por el artículo 568 del código vigente ha sido dividida en dos figuras (artículo 765 y 766) comprendiéndose en la primera el acto homosexual, y en la segunda, los demás actos deshonestos. Ese desdoblamiento permite deslindar con mayor propiedad la homosexualidad consentida o violenta, de la comisión de otros actos deshonestos de menor gravedad y adecuar las sanciones a cada una de las hipótesis" (Reglamento LM - 1-Ejército Argentino, f. 71).

Pero ¿qué era considerado "delito de homosexualidad"? Como señala Máximo Fernández,

\footnotetext{
${ }^{7}$ El artículo 765 fue incluido en el año 1951 con la sanción de la ley 14.029 que, al mismo tiempo, instituyó un nuevo Código de Justicia Militar.
} 


\section{Jazmín Lavintman - Victoria Álvarez}

"Con seguridad, los actos sexuales que conllevaban la penetración anal caían en la órbita del artículo 765. Las situaciones que generaban confusión eran aquellas que no implicaban la penetración pero que, sin embargo, eran detallados como actos sexuales: masturbaciones mutuas, sexo oral, toqueteos, caricias, entre otros. Los defensores solían interpretar que estos actos quedaban contemplados en el artículo 766 pero, en general, los fiscales y los tribunales militares expresaban que el artículo 765 no exigía el 'acto sexual completo'”' (Fernández, 2018: 7).

Sin embargo, al analizar las condenas, podemos ver una considerable disparidad de criterios en las sentencias. ${ }^{8}$

Por otra parte, cabe señalar que, si bien las penas podían variar en función de la condición dentro de la Fuerza (es decir, si eran oficiales, suboficiales o soldados), esta normativa incluía dentro de la categoría de "acto homosexual" tanto las relaciones consentidas entre personas del mismo sexo como el abuso o violencia sexual, sin establecer distinción en el tipo de delito para uno y otro caso. Dicho de otro modo, el delito contra el honor militar consistía en el hecho de que la relación sexual se diera entre dos personas del mismo sexo sin diferenciar si ésta había sido consentida o no. En este sentido, la importancia del desdoblamiento de los artículos 765 y 766 para la institución era diferenciar la gravedad del delito en los términos de cuánto se había avanzado en relación a los actos homosexuales, sin importar la forma en que dichas relaciones se dieran.

Asimismo, entre los casos que expondremos se pueden ver otras formas de categorizar los hechos, como el delito de "corrupción" en relación a casos de relaciones homosexuales que involucren a menores de 18 años, así como la figura de "abuso de autoridad" cuando el abuso se daba bajo órdenes de un superior jerárquico a un subalterno.

Como señalábamos, en el Archivo Histórico de la Justicia Militar se encuentran una gran cantidad de causas por "delito de homosexualidad" 9 . Sin embargo, muchos de estos presentan rasgos de abuso sexual, particularmente de personal jerárquico hacia los subalternos o la tropa. Si bien no están así analizados por la propia justicia militar, ahondaremos en los elementos que se desprenden de los documentos para dar cuenta de esos rasgos e interpretarlos en esa clave. A pesar de la ausencia de categorías específicas en la justicia militar para su juzgamiento, este tipo de prácticas abusivas se daban con frecuencia. Como sostiene Rita Segato, la gramática de los cuerpos tiene una incidencia significativa en la formación y en la constitución subjetiva de los miembros de las Fuerzas Armadas y las Fuerzas de Seguridad argentinas y "la domesticación sexual tiene también como rasgo conjugar el control no solamente físico sino también moral de la víctima y sus asociados" (Segato, 2004: 12). Por último, no debemos perder de vista para muchos casos la dimensión de clase que permite analizar el uso de la violencia y que permite explicar, entre otras

\footnotetext{
${ }^{8}$ No ahondaremos en esta diversidad por no ser el objetivo central de este artículo. Véase Fernández (2018)

${ }^{9}$ El fondo documental de la justicia militar contiene una gran cantidad de documentos realizados contra personal militar por diferentes faltas al Código de Justicia Militar, de una gran riqueza para estudiar a las Fuerzas Armadas en distintos períodos y en función de diferentes ejes.
} 


\section{Delitos contra el honor militar. Homosexualidad y violencia sexual en causas militares durante la última dictadura (1976-1983)}

cosas, por qué la mayoría de los sumarios se abría contra sujetos subalternos dentro de la estructura jerárquica.

Los casos analizados pertenecen uno al Ejército y el otro a la Armada argentina, la selección de ambos se realizó con el criterio de ahondar en situaciones disímiles para analizar la forma en la que la justicia militar trataba la homosexualidad en el seno de la institución. Para el caso de la Fuerza Aérea, se relevaron también tres sumarios caratulados como "violación" pero no fueron incluidos debido a que respondían a denuncias de mujeres civiles por abuso sexual por parte por miembros de la Fuerza10.

Por otra parte, es importante mencionar que no se han encontrado casos de delitos contra el honor llevados a cabo por oficiales, probablemente debido al hecho de que la oficialidad tenía sus propios tribunales de honor, tal como establecía la ley 19.101 de 1971. El artículo 7 postulaba: "son deberes esenciales impuestos por el estado militar para el personal en situación de actividad la sujeción a la jurisdicción militar y disciplinaria y además, para el personal superior, a la jurisdicción de los tribunales de honor". En este sentido, se generaba un fuero particular para la oficialidad y sus delitos contra el honor militar, excluyendo a los suboficiales, quienes sí eran juzgado en la justicia militar por dichos delitos, como veremos en los casos a continuación.

\section{"Problemas de homosexualidad" y la heteronormatividad a contrapelo}

El primer caso que presentaremos corresponde a la Fuerza Armada Argentina. Se trata de un sumario de tres cuerpos bajo la carátula de "delitos contra el honor militar y corrupción cometidos por personal del Portaaviones ARA 25 de mayo". Es un expediente que contiene varios casos en los que, en muchas instancias, se encuentran entremezcladas las declaraciones y la información. Por una cuestión de extensión nos centramos especialmente en dos casos incluidos en el sumario ${ }^{11}$.

El primer caso en el que nos detendremos se sitúa en enero de 1978, en el Cuartel Base de Puerto Belgrano y consiste en la acusación de los cabos Bonell, Pereyra y Romano ${ }^{12}$ contra el Cabo Principal Cuestas. Los tres cabos denunciaron que Cuestas los había citado en su camarote para tener relaciones sexuales, a las que ellos se habían negado. El primero en declarar fue el cabo Bonell, de 17 años de edad, quien denunció la situación el mismo día que ocurrió:

\footnotetext{
"El 20 de enero de 1978 a las 10 hs, cuando me encontraba en la puerta lateral de la cuadra 10, fui observado por el encargado de la misma el CPCA ${ }^{13}$ Cuestas, por estar vestido con pantalones cortos y tener colocada una vincha sobre mi cabeza. Me manifestó que ese no era el uniforme que correspondía a un cabo segundo y que después lo viera" (Sumario 335411, pág 12).
}

\footnotetext{
10 Para un análisis de estos sumarios ver: Alvarez, V. (2018).

11 El documento tiene una extensión de 1.000 fojas.

12 Si bien los archivos son de consulta pública, por la ley de habeas data nro 25236, utilizaremos seudónimos para referirnos a todas las personas implicadas en las causas de las que daremos cuenta. 13 Cabo Principal de Control de Averías.
} 
En su declaración, Bonell mencionaba que, al no recibir una orden concreta, no la cumplió y que, por la tarde, el Cabo Segundo Romano le avisó que Cuestas lo estaba esperando:

\begin{abstract}
"Al apersonarme ante él, el cabo Cuestas me llama por mi nombre, manifestando conocerme pero no recordar con exactitud de dónde, a lo que manifesté que podía ser de la Escuela de Mecánica ... Fue entonces cuando me invitó a continuar la conversación en su camarote, hacia dónde nos dirigimos. Una vez en su interior el cabo Cuestas procede a cerrar la puerta con llave y cerrar las cortinas oscureciendo la habitación, volviendo a retomar la conversación iniciada, derivando en las causales por las que actualmente me encuentro detenido preventivamente. Fue así como le conté mi situación provocada en manifestaciones del cabo Pereyra que me acusa de haber mantenido relaciones sexuales con él, en su condición de homosexual pasivo ${ }^{14}$, teniendo vinculación en este hecho el Cabo Romano. El cabo tomó nota de los nombres, manifestando la intención de tener una entrevista, posteriormente le preguntan si había vuelto al camarote de Cuestas y responde que sí, donde manifestó que su intención era mantener relaciones sexuales con Pereyra y Romano, pero no conmigo, a lo que contesté que si era esa su intención que se lo propusiera" (Sumario 335411, Paquete 56, p. 14).
\end{abstract}

Si bien la redacción dentro del sumario es confusa y la información se encuentra desordenada, podemos extraer varias cuestiones. Lo primero es que un superior le llama la atención al cabo Bonell por su forma de estar vestido, con un short y una vincha en la cabeza. Además, que Bonell efectivamente se encontraba en prisión preventiva en la unidad por las declaraciones de otros dos cabos (Pereyra y Romano) quienes habían denunciado haber tenido relaciones sexuales con él. Esa habría sido la razón por la cual el Cabo Cuestas los había llamado a aquellos tres cabos y había anotado sus nombres en un cuaderno. Llama la atención también que, según se señala en la declaración, Cuestas cerrara todo con llave, y que esta misma observación la hicieran varios marineros a lo largo de sus declaraciones.

Al avanzar en la lectura del sumario vemos que posteriormente declaran situaciones similares los otros cabos (también menores de edad). Retomaremos especialmente una de estas declaraciones: la del Cabo Romano, quien -al momento de los hechos denunciados- se encontraba también en la unidad en prisión preventiva. En su denuncia, Romano señalaba que, una vez en el camarote, Cuestas le había preguntado la razón de su detención y expresaba:

"A lo que respondí que tenía problemas de homosexualidad. Es en esa

\footnotetext{
14 Generalmente, en estos sumarios ocupa un lugar central el rol sexual ocupado en el encuentro sexual. En algunos sumarios, la posición insertiva o activa no parece cuestionar la identidad masculina del sujeto, mientras que el rol receptivo o pasivo sí parece significar la "desviación" sexual. Sin embargo, en la mayoría de estos archivos, como señala Máximo Fernández, aunque la distinción entre 'activo' y 'pasivo' siempre se marcara, la homosexualidad parecía constituir, más allá de la distinción, "el mismo problema de fondo" (Fernández, 2018: 5). Distintos autores lo refieren como el modelo "loca-chongo" (Rapisardi \& Modarelli, 2001; Sívori, 2005; Perlongher, 1999); otros, de relaciones jerárquicas (Fry,1982; Green, 1999); o identidades tradicionales (Motta, 2001).
} 


\section{Delitos contra el honor militar. Homosexualidad y violencia sexual en causas militares durante la última dictadura (1976-1983)}

circunstancia en que el cabo me propone mantener relaciones sexuales con él, requerimiento que no acepté. Ante mi actitud, me solicitó que llamara a Pereyra y Bonell a fin de llegar a un arreglo con éstos que le permita concretar sus propósitos" (Sumario 335411, Paquete 56, p. 19).

Es notoria la afirmación de sí mismo y de su orientación sexual que expresa Romano al plantear que él "tenía problemas de homosexualidad". A partir de la lectura de este documento no podemos saber si efectivamente esta era su autopercepción o si era lo que decía por el contexto en el que se encontraba. Pero, a fin de cuentas, esta afirmación junto con el hecho de que la homosexualidad fuera considerada un delito contra el honor militar, nos permite entrever las concepciones mayoritarias circulantes en las Fuerzas Armadas sobre las relaciones entre personas del mismo sexo.

La última declaración corresponde al Cabo Principal Cuestas, quien negó "haberse entrevistado" con los cabos Bonell, Pereyra y Romano. En este caso, en los considerandos, la justicia militar dio por ciertas las denuncias, concluyendo en relación al accionar de Cuestas que:

"Aprovechando el estado de inferioridad de estos individuos, procura saciar sus instintos fisiológicos tratando alevosamente de proveerse de un goce sexual anormal, en abierto desprecio por la dignidad, la moral y el respeto hacia sus semejantes y la institución de la cual forma parte" (p. 25).

Respecto al estado de inferioridad que menciona el tribunal militar puede estar refiriendo, por un lado, a que él era el superior en términos de la jerarquía militar y etaria y, por otro, referirse a la homosexualidad de los mismos. Por otra parte, el "abierto desprecio a la dignidad, la moral y la institución de la cual forma parte" se relaciona concretamente con su orientación sexual, en contra de las indicaciones de heterosexualidad establecidas por las Fuerzas y así, desde esta perspectiva, iría contra de la institución en general y de los individuos en particular.

En julio de 1978 la causa se elevó al Consejo de Guerra donde se les volvió a tomar declaraciones a los denunciantes y al imputado, realizando careos entre las diferentes versiones. Sin llegar a una conclusión en este hecho ya que Cuestas negaba los hechos sistemáticamente. El Consejo decidió unificar esta causa con otra que tenían en trámite referida al mismo causante: Cuestas.

El caso que se adjunta a la causa mencionada es previo temporalmente, y se anexa a partir de la siguiente información:

"El cabo Cuestas reconoció haber tenido un proceder poco habitual a bordo del portaaviones ARA ${ }^{15}$ durante $1977 . . .$, hacer proposiciones deshonestas para realizar actos homosexuales al marinero Tresei, en calidad de broma y presuntamente haber realizado un coito anal como activo con el cabo segundo Avalos" (Sumario 335411, Paquete 56, p. 87).

15 Armada. 


\section{Jazmín Lavintman - Victoria Álvarez}

La denuncia referida a esta segunda causa había transcurrido en otra Unidad de la Armada: el Portaaviones 25 de Mayo, entre 1976 y 1977 e incluía a otros marineros y cabos más. En el marco de acusaciones contra Cuestas, debido al desenlace de esta causa y por una cuestión de extensión, nos centraremos en la declaración de Ávalos sobre la relación sexual que denuncia con Cuestas.

Ávalos fue interrogado específicamente sobre su orientación sexual y sobre su desempeño sexual mientras prestaba servicio en la Fuerza. En su declaración él señaló: "antes de la ESMA ${ }^{16}$ tuve diferentes experiencias desde alrededor de los 4 o 5 años (sic). En el año 1975 en un baño de la ESMA y en la navegación con Ledesma" (Sumario 335411, Paquete 56, p. 142). Y agregaba que en una oportunidad Cuestas lo había llamado y le había ofrecido tener relaciones sexuales y que él siempre se había negado. Sin embargo, señalaba que un día Cuestas había logrado convencerlo. En esta primera declaración Ávalos afirmó haber tenido relaciones sexuales con diferentes personas dentro de la ESMA -que era su destino anterior- y del Portaviones 25 de mayo. En mayo de 1977 Ávalos fue diagnosticado con "personalidad psicopática tipo homosexual" y lo declararon "inepto para todo servicio. Con afección descubierta en servicio pero no consecuencia de él" (Sumario 335411, Paquete 56, p. 110). En ese contexto, declaró haber mantenido relaciones sexuales con Cuestas, quien le había hecho varias proposiciones previas y que nunca había aceptado,

"Hasta que una noche, a la 1 AM, una patrulla lo hizo despertar por el cabo. Y que en aquella oportunidad aceptó, siendo finalmente "introducido" por el causante. Que luego volvió a ser objeto de las proposiciones y se negó en las diversas oportunidades en razón de no querer tener relaciones con dicho cabo" (Sumario 335411, Paquete 56, p. 157).

En diciembre de 1978 la justicia militar pidió la detención de Ávalos, quien ya se encontraba de baja de la Fuerza. Luego de su detención le volvieron a tomar declaración, sobre las relaciones homosexuales mantenidas con personal militar que había declarado en 1977. Sin embargo en esa ocasión, Ávalos las negó, sostuvo que nunca mantuvo relaciones homosexuales y que denunció a su superior de la ESMA porque "le tenía bronca ya que nos tenía cortitos en la Escuela de Mecánica y siempre nos bailaba17". Respecto a las causas de sus declaraciones generales, contestó que no le gustaba la vida militar y agregó: “[un día] no aguanté más y entonces decidí decirle a mi superior que era homosexual. Declaré lo de Cuestas y como vi que mucho no me creía, inventé todo lo demás". Más adelante señaló: "Yo no sabía que con esas acusaciones estaba acusando a ellos de un delito contra el honor militar... Tenía desesperación por irme de baja". Luego agregó: "me caían mal las formaciones, las inspecciones, en fin, todo me caía mal” (Sumario 335411, Paquete 56, p. 144).

\footnotetext{
${ }^{16}$ Escuela de Mecánica de la Armada (en adelante, ESMA)

${ }^{17}$ Bailar, en la jerga militar, consiste en castigar y disciplinar a los soldados sometiéndolos a ejercicios físicos extenuantes a cualquier hora del día y sobre cualquier superficie.
} 


\section{Delitos contra el honor militar. Homosexualidad y violencia sexual en causas militares durante la última dictadura (1976-1983)}

Llegamos aquí al punto que más interesante nos resulta del extenso sumario: en conclusión, según el mismo Ávalos señalaba, habría utilizado la normativa sobre el "honor militar" (aunque sin conocerla en profundidad) para dejar de prestar servicios en la Armada porque estaba desesperado por irse de la institución. Aun sabiendo que podía ser detenido por la supuesta homosexualidad, hizo jugar en sentido favorable para sí la heteronormatividad impuesta por la legislación militar, apropiándose de su discurso para dejar la Armada. Si, en efecto, así hubiera sido, podemos ver una actuación subversiva por parte de Ávalos, una ejecución a contrapelo de la heteronorma y del papel previsto por la gramática generizada de la justicia militar, en el marco de las Fuerzas Armadas y el terrorismo de estado. Volveremos sobre este punto en las conclusiones. Es probable que otras formas de irse de la Armada fueran más peligrosas para él en el contexto del terrorismo de Estado que declararse homosexual para ser expulsado de la misma.

Finalmente, la defensa de Ávalos señaló su "iniciación homosexual con una violación en la adolescencia lo que determina su conducta futura", indicando que el mismo debía ser declarado inimputable. Sin embargo, Ávalos estuvo en prisión preventiva desde enero de 1979 hasta la sentencia del Consejo de Guerra en mayo de 1980, cuando lo condenaron como autor del delito contra el honor militar con el atenuante de ser menor de 18 años (Sumario 335411, Paquete 56, p. 961). En un oficio de agosto de 1980 del comandante de la Armada Almirante Armando Lambruschini resolvió que se diera por cumplida la sentencia.

\section{Violencia sexual en la formación militar}

El segundo caso que analizaremos, a modo de contrapunto, es una denuncia realizada por el soldado conscripto Perez contra el cabo Giménez que la justicia militar catalogó como "abuso de autoridad". La denuncia se relaciona con una serie de acontecimientos ocurridos el día 29 de abril de 1977 en Loma Pelada. El soldado conscripto denunció que su pelotón de instrucción había sido llevado desde el polígono de tiro hacia el Riachuelo,

\footnotetext{
"ejecutando movimiento de orden cerrado, una vez en el citado río -el Cabo- nos ordenó subir y bajar la barranca del mismo y como en vez de subir y bajar corriendo como el cabo había ordenado, lo hacía al trote porque estaba cansado, me amenazó diciendo que si no corría me iba a hacer culear con todos. Como yo estaba cansado y seguía trotando me hizo descender la barranca, ordenándome que me quitase el pantalón y me tire cuerpo a tierra, a los demás soldados que saquen el pene y que alguno baje y me suba, bajó uno y me subió yo me corrí, luego me hizo bajar el calzoncillo y preguntó a los demás quién tiene el pene erecto, y bajó a otro soldado que no sé quién es, éste quiso subirme yo me senté, entonce (sic) ese fue y ordenó lo mismo a un tercero, cuando este vino yo le dije hacete el estúpido que yo no quiero que pase nada y él me contestó que eran órdenes, yo seguí sentado (sin acostarme boca abajo), le ordenó a ese tercero "por lo menos metele el dedo", el soldado se levantó y el cabo lo hizo subir y yo me vestí" (Sumario 79666 EA, paquete 212, p.2).
} 
Como el hecho fue presenciado por todo el pelotón, la justicia interrogó a cada uno de los conscriptos y soldados que habían estado presentes. En ese marco, declaró el soldado Saavedra, relatando los acontecimientos de un modo muy similar:

"el Cabo le dijo que se mueva más rápido o si no lo iba a hacer cojer [sic] con todos los soldado [sic], como el citado soldado no podía correr más rápido, le ordenó descender y bajarse los pantalones y me llamó a mí con el pene afuera para que lo subiera, como yo me negaba él me insistió o si no nos iba a bailar ${ }^{18}$ a todos, entonces yo me tiré encima pero no le hice nada, después el cabo Gimenez lo llamó al soldado Guerrero, ordenándole lo mismo y éste se le tiró encima pero como el otro no se dejaba le gritó "aunque sea metele el dedo", después nos trajo al polígono otra vez" (Sumario 79666 EA, paquete 212, p.3).

Por su parte, otro soldado conscripto, especificó que:

"estaban en el polígono y el cabo Gimenez llamó a dos soldados, fueron los dos, él vino y dijo que cuando él llama a un soldado tiene que venir la compañía completa y por esa causa nos llevó hacia el riacho, ejecutando movimientos vivos, haciéndonos subir y bajar la barranca del río, el soldados Almada estaba cansado y trotaba, entonces el cabo dijo 'que si no corría le iba a hacer coger por todos los soldados del pelotón, que todos estaban lechudos y que hacía un mes que no cojían [sic]" (Sumario 79666 EA, paquete 212, p. 5).

Sin embargo, quién terminó de explicitar la situación fue el propio cabo Gimenez, que afirmó que llamó a dos soldados del grupo para limpiar armamento:

"Lo hice ejecutar movimientos vivos con el resto del pelotón en dirección al río, y le dije que iban a conocer la subida y bajada de la loma. El soldado Ávalos iba al paso, le dije que se mueva más rápido y siguió al paso, lo tuve cinco minutos más y el soldado seguía con el mismo ritmo. Como veía que él no corría lo llamé y le dije 'que le iban a agarrar todos los soldados que andaban muy lechudos', luego le ordené que se saque el pantalón y el resto de los soldados que se saquen el pene pero ninguno lo hizo, lo llamé al soldado Saavedra para que lo heche (sic) al soldado Perez, éste había quedado con el calzoncillo colocado y le dije a Saavedra que lo clavara, pero Perez se resistía y entonces le ordené al mismo que se saque el calzoncillo, cumplió la orden, le ordené nuevamente a Saavedra que se tirara sobre él y éste lo sacó de un manotazo, como la víctima seguía resistiendo le dije que le meta el dedo, pero el soldado le tocó solamente las piernas, en ese momento apareció el Cabo Domasi llamándome y le ordené al resto de los soldados que se vayan con el Cabo Domasi" (Sumario 79666 EA, paquete 212, p. 7).

En el dictamen que eleva la unidad al comandante de la Brigada, comentaba los hechos y afirmaba: "los soldados conscriptos Saavedra y Giménez son los soldados que por orden del imputado debían cometer la vejación, la cual no se produce porque la víctima se resiste" (Sumario 79666 EA, paquete 212, p. 13). El cabo Giménez resultó inculpado por abuso de autoridad (artículo 702, inc 20). En ese

${ }^{18}$ Cfr. nota 7 


\title{
Delitos contra el honor militar. Homosexualidad y violencia sexual en causas militares durante la última dictadura (1976-1983)
}

marco, le volvieron a tomar declaración indagatoria, pero esta vez le preguntaron por la intencionalidad de las órdenes y los hechos sucedidos, a lo que respondió que su intención era atemorizar a la víctima (Sumario 79666 EA, paquete 212, p. 14). Por último, le volvieron a tomar declaración al soldado Pérez, quien realizó una descripción más detallada de toda la situación, señalando que

\begin{abstract}
"habiendo finalizado de rendir la condición de tiro se ubicó, juntamente con 20 compañeros de un pelotón y que se encontraba en descanso (...) en ese momento se acercó el cabo Gimenez y preguntó "Quién tiene armamento" y en razón del ruido producido por la actividad de tiro, al parecer escuchó un solo integrante del mismo. (..) ante esto le manifestó que les había preguntado a todos, razón por la cual le ordenó al pelotón la realización de una serie de movimientos vivos. Mientras estos se realizaban fueron orientados en dirección al Riachuelo. Transcurridos 15 min el declarante se encontraba cansado y en circunstancias que por los motivos dichos, cuando se le ordenó carrera el tan solo estaba en condiciones de trotar, fue llamado por el cabo Gimenez quien le manifestó "si no corrés te voy a hacer culear por todos". El declarante interpretó esto como un chiste de muy mal gusto. Continuó con la ejecución de movimientos vivos en una pendiente haciendo ascender y descender a los soldados. Esto concluyó con las fuerzas del declarante que llegado un momento no pudo seguir. Todos habían quedado en la parte superior de pendiente y en esas circunstancias le ordenó al declarante que descendiera, y se bajara la bombacha. Si bien este dudó, interpretó que el cabo Gimenez seguía con la broma y, para evitar que el no cumplimiento de la orden podia acarrearle males mayores cumplio la orden. Cumplió la orden, se bajo hasta las rodillas y ordenó a todos que saquen el picho y pelen. Nadie cumplió la orden. Entonces le ordenó a Saavedra que descendiese y se subiera arriba. Luego hizo bajar a otro, el soldado víctima se resistió. Acto seguido y dirigiéndose al pelotón el suboficial inquirió quien tenía el pito parado y como nadie respondió ordenó a un tercer soldado que descendiese hacia donde se encontraba el declarante. Así lo hizo descendiendo y dado que no tenia ereccion le ordenó al soldado "por lo menos metele el dedo en el culo" cuestión que el soldado trató de realizar, impidiéndole el declarante" (Sumario 79666 EA, paquete 212, p. 19).
\end{abstract}

En la elevación del caso en un informe a la instancia superior, se propuso que inculparan a Gimenez por el delito de abuso de autoridad, pero también se indicó la necesidad de juzgar al soldado víctima, cuando la propia justicia había tipificado los hechos como vejación, afirmando que:

"Habiéndose ordenado la realización con su vestuario personal de una serie de actividades que entrañaban una afrenta a su hombría, no reaccionar debidamente y ejecutar las misma por temor a una represalia personal, demostrando con su proceder no poseer un cabal sentido de la ética y sentido del honor que deben caracterizar a la persona humana ante manifestaciones reñidas con principios elementales de la moral, con la atenuante de estar recientemente integrado" (Sumario 79666 EA, paquete 212, f. 36)

Luego, se proponía lo mismo en relación a los soldados Saavedra y Guerrero por no haberse resistido a las órdenes del cabo. Es decir que se consideraba que, tanto Pérez (el denunciante) como Saavedra y Guerrero tenían que demostrar que habían resistido; de no ser así, también obtendrían una condena. Es decir que el daño 


\section{Jazmín Lavintman - Victoria Álvarez}

sufrido por la víctima se volvía subsidiario de otro que ocupaba el centro de la escena: la degradación del honor de la institución, pasando a un segundo plano el sufrimiento de la víctima.

Como ha analizado Silvia Chejter (1990), en el imaginario social -así como fundamentalmente en el judicial- se suele dar un doble mensaje que convierte a la víctima de la violencia sexual en una persona altamente sospechosa e indigna de crédito: no sólo debe probar que ha sido agredida - a diferencia de las víctimas de otros delitos- sino que también debe probar que no provocó la situación que denuncia. Así, "El fantasma de la falsa denuncia planea continuamente y en primer lugar, como si el predador fuera la víctima tendiendo sus redes y no el agresor" (Chejter, 1990: 109). Esta suspicacia resulta siempre decisiva para la conformación del cuerpo del delito y para convertir a la víctima en el principal sujeto a investigar. Esta inversión gira en torno a las ideas de consentimiento y resistencia, las costumbres de la víctima, sus precauciones para evitar el hecho, sus reacciones durante y después del hecho, entre otras cosas.

\section{Conclusiones}

Los dos sumarios del Archivo Histórico de la Justicia Militar que hemos analizado permiten reflexionar sobre algunas cuestiones que resultan de nuestro interés. En primer lugar, un aspecto que subyace es la forma en que la dimensión de clase pudo haber intervenido en la producción de sentidos sobre la sexualidad masculina. En las causas analizadas, el juzgamiento imputaba frecuentemente a sujetos subalternos dentro de la estructura militar; es decir, a un grupo social conformado por varones provenientes generalmente del interior del país y fundamentalmente de clases populares.

Desde ya, merece una mención la legislación militar evidentemente heteronormativa que, como hemos visto, consideraba las relaciones sexuales entre personas del mismo sexo como un delito "contra el honor militar" y le asignaba la pena de prisión en la mayoría de los casos, así como en ocasiones la baja de la institución. Resaltamos también la escasa atención que se le presta a las condiciones en las que se dieron esas relaciones, fundamentalmente al hecho de si fueron consentidas o no.

En ese sentido, el primer caso analizado nos resulta especialmente interesante por lo que significa en términos de agencia: en el mismo podemos ver cómo la rigidez de la normativa pudo haber sido utilizada por un soldado que, en plena dictadura militar, quería a toda costa dejar de prestar servicios en las dos unidades en las que había estado destinado (la ESMA y el POMA) por lo que había optado por declararse homosexual, someterse a la prisión preventiva y -seguramente- ser despreciado por compañeros y superiores, a fin de irse de la Armada evitando problemas de otro tipo (probablemente, más graves, teniendo en cuenta el contexto de terrorismo de Estado). Podemos ver en este caso, como decíamos, un uso subversivo de la norma: 


\section{Delitos contra el honor militar. Homosexualidad y violencia sexual en causas militares durante la última dictadura (1976-1983)}

según parece indicar el sumario, el cabo Ávalos habría hecho jugar en sentido favorable para sí las reglas heteronormativas impuestas por la justicia militar, apropiándose a contrapelo de ellas para dejar la Armada.

Pero al mismo tiempo, más allá de la rigidez de las normas, vemos que los "delitos contra el honor militar" y, particularmente, el abuso sexual, eran mucho más corrientes de lo que se aparentaba en el plano discursivo y normativo. Como señala Máximo Fernández,

\footnotetext{
"en contraste con la escalada represiva del periodo, el éxito de las Fuerzas Armadas en la construcción de una masculinidad hegemónica distaba mucho de ser una realidad en las décadas de 1960 y 1970. Antes que un discurso articulado $o$ un dispositivo bien engranado, el análisis de los sumarios militares por los juicios contra el "honor militar" devuelve una imagen más equívoca y difusa sobre el control de la sexualidad masculina" (Fernández, 2018: 2).
}

Si bien, por una cuestión de extensión sólo hemos podido analizar dos casos, como decíamos, hay una cantidad considerable de denuncias de características similares en el Archivo Histórico de la Justicia Militar. Y debemos tener en cuenta que, en cuanto a los casos de abuso sexual, como ha señalado Silvia Chejter, cuando analizamos los expedientes judiciales, las conclusiones que podemos sacar no tienen que ver tanto con el fenómeno de la violación en sí sino más bien con aquel construido por el derecho y las prácticas judiciales. "Son la realidad social y las políticas de control y represión social -mediadas por el imaginario social- las que funcionan como un filtro que divide las conductas delictivas de las que no lo son" (Chejter 1990: 28), por lo que siempre llega a la justicia sólo un minoritario número de casos de abuso sexual en relación al total.

En los dos casos que desarrollamos en este trabajo estos filtros resultan evidentes: las víctimas debían someterse a careos, en muchos casos eran trasladados, apresados o dados de baja de la fuerza (lo que, justamente, quería el denunciante en el primer caso). Como señalábamos más arriba, lo central de la normativa resulta ser la "degradación del honor de la institución", pasando a un segundo plano si se trató de una relación consentida o no, entre otras cosas.

Asimismo, debemos destacar la naturalidad con la que los distintos testimoniantes hablan de los hechos, principalmente el militar denunciado -Giménez-relataba los acontecimientos con una falta de inhibición que no deja de llamar la atención, por lo que podemos suponer que, en la formación militar las distintas formas de abuso sexual no constituían excepciones. Respecto de la situación denunciada en el segundo caso, se puede ver claramente una búsqueda del castigo mediante la feminización producida con el abuso sexual frente a todos sus compañeros. Llama la atención que el propio denunciado comentaba: "como veía que él no corría lo llamé y le dije que le iban a agarrar todos los soldados que andaban muy lechudos", es decir que de los compañeros que podía entrenar se destacaban sus características masculinas y, al que no podía hacerlo, se le indicaba que se bajara "la bombacha" y se sometiera al abuso sexual por parte de sus compañeros. No solamente vemos una 


\section{Jazmín Lavintman - Victoria Álvarez}

práctica de subordinación mediante el abuso sexual sino que, como decíamos, por la forma en la que todos declaraban, podemos intuir que estas prácticas distaban mucho de ser excepcionales.

En definitiva, encontramos en el plano normativo discursos fuertemente cis heteronormativos pero, al mismo tiempo, se hacen evidentes una gran cantidad de prácticas subordinantes mediante la violencia (homo) sexual. Siguiendo a Rita Segato, podemos entender a estas formas de violencia sexual como formas de castigo, actos expresivos moralizantes que se dirigen a un varón (subordinado en términos de jerarquía militar y de clase) -feminizado, mediante el acto de la violencia sexual- que, desde la perspectiva de los victimarios, "se salió de su lugar" (Segato, 2003). Finalmente, la noción de una masculinidad sexualmente agresiva e incontrolable constituía un telón de fondo (Fernández, 2018). Y, si bien la oficialidad militar sancionaba moralmente la falta de control de ese "instinto viril", nadie ponía en cuestión su existencia.

\section{Referencias bibliográficas}

Acha, 0. y Ben, P. (2004). Amorales, patoteros, chongos y pitucos. La homosexualidad masculina durante el primer peronismo. Trabajos $y$ comunicaciones (30-31). Recuperado de: http://www.memoria.fahce.unlp.edu.ar/library?a=d\&c=arti\&d=Jpr316

Alvarez, V. (2018). Denuncias y marcos de escucha para la violencia sexual en tribunales militares durante la última dictadura argentina (1976-1983). Revista de estudios de género, La Ventana (48). Recuperado de: http://revistalaventana.cucsh.udg.mx/index.php/LV/article/view/6796

Alvarez, V. (2015). Género y violencia: Memorias de la represión sobre los cuerpos de las mujeres durante la última dictadura militar argentina. Nomadías (19). Recuperado de: https://nomadias.uchile.cl/index.php/NO/article/view/36763

Andújar, A., D’Antonio, D., Dominguez, N., Grammático, K., Gil Lozano, F., Pita, V. y Vassallo, A. (Comps.) (2005). Historia, género y política en los '70. Buenos Aires: Feminaria Editora.

Chejter, S. (1990). La voz tutelada. Violación y voyeurismo. Montevideo: Nordan.

D’Antonio, D. (2016). Los Consejos De Guerra Durante La Última Dictadura Militar Argentina (1976-1983). Iberoamericana - Nordic Journal of Latin American and Caribbean Studies (45). Recuperado en: https://www.iberoamericana.se/articles/10.16993/iberoamericana.3/ 


\section{Delitos contra el honor militar. Homosexualidad y violencia sexual en causas militares durante la última dictadura (1976-1983)}

D’Antonio, D. (2014) Deseo y represión. Sexualidad, género y Estado en la historia reciente. $1^{\circ}$ ed. Buenos Aires: Imago Mundi.

Fernández, M. J. (2018). Nadie puede juzgar qué es bueno y qué es malo. Sexualidad masculina y sexo entre varones en los delitos contra el honor militar en la Armada Argentina, 1960-1980. Sexualidad, Salud y Sociedad (Rio de Janeiro), (29). Recuperado en: https://dx.doi.org/10.1590/1984-6487.sess.2018.29.03.a

Fernández, M. J. (2015) "Sociabilidad homoerótica en la ciudad de Buenos Aires: maricas y marineros durante los sesenta y los setenta" en D'ANTONIO, Débora (Comp.); Deseo y represión. Sexualidad, género y Estado en la historia reciente. Buenos Aires: Imago Mundi.

Filc, J. (1997). Entre el parentesco y la política: familia y dictadura, 1976- 1983. Buenos Aires: Biblos.

Fry, P. (1982). Para inglês ver. Identidade e política na cultura brasileira. Rio de Janeiro: Zahar.

Green, J. (1999). Beyond Carnival. Male homosexuality in twentieth-century Brazil. Chicago: University of Chicago Press.

Insasuti, S. J. (2015). Los cuatrocientos homosexuales desaparecidos: memorias de la represión estatal a las sexualidades disidentes en Argentina. En D. D’Antonio, (Comp.); Deseo y represión. Sexualidad, género y Estado en la historia argentina reciente. Buenos Aires: Imago Mundi.

Motta, A. (2001). Entre lo tradicional y lo moderno: La construcción de identidades homosexuales en Lima. En J. Bracamonte Allaín (comp.); De amores y luchas. Diversidad sexual, derechos humanos y ciudadania. $1^{\circ}$ ed. Lima: Centro de la Mujer Peruana Flora Tristán.

Perlongher, N. (1999). El negocio del deseo: la prostitución masculina en San Pablo. Buenos Aires: Paidós.

Rapisardi, F. \& Modarelli, A. (2001). Fiestas, baños y exilios: los gays porteños en la última dictadura. $1^{\circ}$ ed. Buenos Aires: Sudamericana.

Sívori, H. (2005). Locas, chongos y gays. Sociabilidad homosexual masculina durante la década de $1990.1^{\circ}$ ed. Buenos Aires: Antropofagia.

Segato, R. (2003). Las estructuras elementales de la violencia. Contrato y status en la etiología de la violencia. Brasilia: Serie Antropológica 334.

Segato, R. (2004). Antropología y Derechos Humanos: alteridad y ética en el movimiento de los Derechos Humanos. Brasilia: Serie Antropológica 356. 
Segato, R. (2010). La violencia sexual y el discurso del derecho en M. Sonderéguer y V. Correa (comps.); Violencia de género en el terrorismo de Estado. Políticas de Memoria, Justicia y Reparación. Bernal: Universidad Nacional de Quilmes

\section{Documentos citados}

Sumario 335411, Paquete 56. Serie: ARA. Fondo: Consufa. Departamento de Archivo Intermedio Archivo General de la Nación.

Sumario 79666, paquete 212. Serie: EA. Fondo: Consufa. Departamento de Archivo Intermedio Archivo General de la Nación.

“Código de Justicia Militar. Ley N 14.029" (Reimpresión actualizada). LM - 1, Ejército Argentino. Instituto Geográfico Militar, 1984.

Ley 14.029, Código de justicia militar, 1951.

Ley 19.101 “Ley para el personal militar”, 1971.

Recibido: 10/09/2019

Evaluado:07/10/2019

Versión Final: 07/11/2019 